ARTICLE OPEN

\title{
A prospective cohort study of the use of domiciliary intravenous antibiotics in bronchiectasis
}

\author{
Pallavi Bedi ${ }^{1}$, Manjit K Sidhu ${ }^{1}$, Lucienne S Donaldson ${ }^{1}$, James D Chalmers ${ }^{1}$, Maeve P Smith ${ }^{2}$, Kim Turnbull ${ }^{2}$, Joanna L Pentland ${ }^{3}$, \\ Jenny Scott ${ }^{4}$ and Adam T Hill ${ }^{1,2}$
}

BACKGROUND: We introduced domiciliary intravenous (IV) antibiotic therapy in patients with bronchiectasis to promote patientcentred domiciliary treatment instead of hospital inpatient treatment.

AIM: To assess the efficacy and safety of domiciliary IV antibiotic therapy in patients with non-cystic fibrosis bronchiectasis.

METHODS: In this prospective study conducted over 5 years, we assessed patients' eligibility for receiving domiciliary treatment. All patients received 14 days of IV antibiotic therapy and were monitored at baseline/day $7 /$ day 14 . We assessed the treatment outcome, morbidity, mortality and 30-day readmission rates.

RESULTS: A total of 116 patients received 196 courses of IV antibiotics. Eighty courses were delivered as inpatient treatment, 32 as early supported discharge (ESD) and 84 as domiciliary therapy. There was significant clinical and quality of life improvement in all groups, with resolution of infection in $76 \%$ in the inpatient group, $80 \%$ in the ESD group and $80 \%$ in the domiciliary group. Morbidity was recorded in $13.8 \%$ in the inpatient group, $9.4 \%$ in the ESD group and $14.2 \%$ in the domiciliary IV group. No mortality was recorded in either group. Thirty-day readmission rates were $13.8 \%$ in the inpatient group, $12.5 \%$ in the ESD group and $14.2 \%$ in the domiciliary group. Total bed days saved was 1443.

CONCLUSION: Domiciliary IV antibiotic therapy in bronchiectasis is clinically effective and was safe in our cohort of patients.

npj Primary Care Respiratory Medicine (2014) 24, 14090; doi:10.1038/npjpcrm.2014.90; published online 23 October 2014

\section{INTRODUCTION}

Bronchiectasis is a chronic debilitating respiratory condition. Patients suffer from daily cough, excess sputum production and recurrent chest infections because of inflamed and permanently damaged airways. It is a common condition, with an incidence of 1 in 1,000 in Scotland. Management of bronchiectasis consists of airway clearance and prompt treatment of infections with antibiotics, administered intravenously in more severe cases.

There is evidence that patients with bronchiectasis who have more frequent exacerbations have worse quality of life. ${ }^{1}$ The current British Thoracic Society (BTS) guidelines for non-cystic fibrosis bronchiectasis recommends antibiotics for exacerbations that present with an acute deterioration (usually over several days) with worsening local symptoms (cough, increased sputum volume or change of viscosity, increased sputum purulence with or without increasing wheeze, breathlessness, haemoptysis) and/or systemic upset. ${ }^{2}$

Over 720 bronchiectasis patients in Edinburgh, UK, are monitored in secondary care. They frequently utilize primary and secondary care resources through consultations, A\&E attendances and inpatient admissions. The economic burden is significantinpatient admissions alone for bronchiectasis in NHS Lothian cost just over $£ 1$ million per year. There is a worldwide drive for the domiciliary management of chronic respiratory diseases like COPD. Outpatient intravenous (IV) therapy has gained widespread acceptance because of its advantages over inpatient hospitalizations, including fewer absences from school or work and less disruption of family life, decreased costs and high patient satisfaction. $^{3-7}$ Outpatient and domiciliary parenteral antibiotic therapy programs are well-recognized and accepted modes of providing healthcare in the community worldwide, but the UK has been relatively slow to adopt this practice. ${ }^{8-10}$

Although domiciliary IV antibiotic therapy has already been implemented in cystic fibrosis, this has not been done in noncystic fibrosis bronchiectasis, where the cohort of patients are middle aged and elderly with comorbid conditions, compared to a relatively younger cohort in cystic fibrosis.

The aim of our study was to evaluate the efficacy and safety of domiciliary IV antibiotic therapy for treating exacerbations of noncystic fibrosis bronchiectasis.

\section{MATERIALS AND METHODS}

\section{Domiciliary IV antibiotic team}

All cases were reviewed by the domiciliary team-comprising one respiratory physician leading the bronchiectasis service in NHS Lothian, one specialist registrar, one clinical nurse specialist, one physiotherapist and one respiratory pharmacist. Patients are referred to the bronchiectasis team by completing an outpatient IV antibiotic referral form specifying the antibiotic to be prescribed for 14 days. If the patient was unwell and required hospital admission he or she was taught how to self-administer IV antibiotics while an inpatient, and if competent was given early supported discharge (ESD). Patients were taught to self-administer IV antibiotics via a cannula, midline catheter or a totally implanted port-the midline catheter was the mode used in the majority of patients. A pall filter is attached to the cannula to aid self-administration. Clear instructions were given to patients on how to flush IV access, make up antibiotics and secure access

\footnotetext{
${ }^{1}$ Centre for Inflammation Research, Queen's Medical Research Institute, Edinburgh, UK; ${ }^{2}$ Department of Respiratory Medicine, Royal Infirmary of Edinburgh, Edinburgh, UK; ${ }^{3}$ Department of Physiotherapy (Respiratory Medicine), Royal Infirmary of Edinburgh, Edinburgh, UK and ${ }^{4}$ Department of Pharmacy (Respiratory Medicine), Royal Infirmary of Edinburgh, Edinburgh, UK.

Correspondence: P Bedi (pallavimandal@googlemail.com)

Received 13 March 2014; revised 17 June 2014; accepted 30 August 2014
} 
once antibiotics were administered. All procedures were done aseptically Patients were taught by the clinical nurse specialist and had to demonstrate the technique of administration of antibiotics to the nurse specialist and were deemed eligible for domiciliary therapy only once the domiciliary team were satisfied with the technique and safety measures. Patients were provided with antibiotics, an epipen in case of anaphylaxis, flushes, syringes, needles, sharps bin, bandages and a patient information booklet. The patients returned at 1 week to be reviewed by the clinical nurse specialist and were provided with a fresh supply of equipment and antibiotics to complete the course of antibiotic therapy. All patients returned for a final visit on day 14 to return left-over equipment and to finish treatment assessment. Patients were given the contact details of the domiciliary team, for them to contact if they had any problems with IV access, adverse reactions or worsening of symptoms. If there were occasions out of clinic hours when a patient presented with problems, the patient would phone the respiratory ward, at Royal Infirmary of Edinburgh, and then would be reviewed by the on-call team. The clinical nurse undertook routine management of outpatients on IV antibiotics and monitored their blood, lines/access devices, sputum, spirometry, incremental shuttle walking test and progress/condition. The medication aspects were supported by the ward pharmacist.

There had to be a unified consensus from the domiciliary team that the patient was suitable for domiciliary IV antibiotic therapy, for safety reasons. Patients were refused by the domiciliary team if they had any of the following features: unable to cope at home; development of cyanosis or confusion; breathlessness, with a respiratory rate $\geqslant 25 / \mathrm{min}$; circulatory failure; respiratory failure; temperature $\geqslant 38^{\circ} \mathrm{C}$; unable to take oral therapy.

If requiring initial hospital admission, patients were considered for ESD if they had none of the above adverse features for $24 \mathrm{~h}$ or longer.

\section{Choice of antimicrobial and drug delivery}

All patients received 14 days of IV antibiotic therapy using antibiotics as per sensitivity testing, and the respiratory physician decided this. Antibiotics were administered by inserting an antecubital peripheral long line catheter.

\section{Study design}

Patients were recruited prospectively over 5 years from December 2006 to December 2011, from the Royal Infirmary of Edinburgh, UK. All patients requiring IV therapy for an acute exacerbation were assessed by the domiciliary IV team for consideration of 14-day domiciliary IV therapy or ESD with domiciliary IV therapy.

\section{Outcome measures - at the start and end of exacerbation}

Outcome measures recorded were treatment outcome (by measuring forced expiratory volume in $1 \mathrm{~s}\left(\mathrm{FEV}_{1}\right)$, forced vital capacity (FVC), incremental shuttle walk test, 24-h sputum volume, sputum microbiology, markers of inflammation-white cell count, C-reactive protein and erythrocyte sedimentation rate, health status questionnaires-Leicester Cough Questionnaire ${ }^{11}$ and St George's Respiratory Questionnaire ${ }^{12}$ ), morbidity, mortality and 30-day readmission rates.

\section{Patients}

Inclusion criteria. Patients were included if they satisfied any of the following criteria: (1) had an established radiological diagnosis of bronchiectasis (high resolution CT scan of the chest); (2) had an exacerbation defined by acute deterioration (usually over several days) with worsening local symptoms (cough, increased sputum volume or change of viscosity, increased sputum purulence with or without increasing wheeze, breathlessness, haemoptysis) and/or systemic upset (3) needed IV antibiotics because of failure to respond to oral antibiotics, having a pathogen requiring IV antibiotic therapy or severe exacerbations necessitating inpatient admission.

Patients who were considered to be suitable for domiciliary IV treatment or ESD had to meet the following requirements: (1) were committed and able to attend the hospital for assessments; (2) were able to demonstrate that they can safely administer IV antibiotics; (3) had home circumstances appropriate for treatment; and (4) had no evidence of potential IV drug abuse.
Lung function

$\mathrm{FEV}_{1}, \mathrm{FVC}$ and $\mathrm{FEV}_{1} / \mathrm{FVC}$ ratio were recorded, according to national guidelines. ${ }^{13}$

\section{Incremental shuttle walk test}

Patients walked a 10-m course mapped out by two cones. The speed gradually increased each minute. The test was stopped if the patient was too breathless or failed to attain the desired speed. The distance walked was recorded in metres. ${ }^{14}$

\section{Health status}

Patients were asked to complete both the Leicester Cough Questionnaire and St George's Respiratory Questionnaire at all review time points. The Leicester Cough Questionnaire has 19 items divided into three domains: physical (8 items), psychological (7 items) and social (4 items). The total severity score ranges from 3 to 21 , where a lower score indicates a greater impairment of health status due to cough. The minimum clinical important difference for the Leicester Cough Questionnaire is 1.3 units. ${ }^{11}$ We have validated the Leicester Cough Questionnaire for use in non-cystic fibrosis bronchiectasis. ${ }^{15}$ The St George's Respiratory Questionnaire has 50 items divided into three main domains: symptoms, activities and impacts. The total score ranges from 0 to 100 , where a higher score indicates a poorer health-related quality of life (HRQoL). The minimum clinical important difference for the St George's Respiratory Questionnaire is 4 units. ${ }^{12}$

\section{Blood samples}

Fifteen millilitres of venous blood was collected and white cell count, erythrocyte sedimentation rate and C-reactive protein were measured.

\section{Complications}

All patients receiving ESD or 14-day domiciliary IV therapy received an information booklet and emergency contact number should they develop any complications.

\section{Successful therapy}

A successful therapy was considered if patients felt back to their usual clinical state and there was objective improvement in sputum purulence and/or a reduction in 24-h sputum volume and/or sputum bacterial clearance. $^{2}$

\section{Statistical analysis}

All data were analysed using Graphpad prism (Graphpad software, San Diego, CA, USA). For demographic and clinical variables, data are presented as median (interquartile range) for continuous variables and $n$ (\%) for categorical variables unless otherwise stated. Comparison of changes within the groups was done using Wilcoxon signed rank test. An analysis of variance was used to compare the groups. Data were complete for all events. A $P$-value of $<0.05$ was considered statistically significant for each analysis.

\section{RESULTS}

Patients were divided into three groups based on where the antibiotic courses were delivered-those who received IV inpatient antibiotic therapy for the 14 days, those who were allowed ESD, and those who received domiciliary IV antibiotic therapy for the 14 days. There were 80 patients who received inpatient treatment for 14 days, 32 had ESD and 84 received the full 14 days of domiciliary therapy (Figure 1). The total patient number represents the total number of antibiotic courses as one patient may have received more than one course of antibiotic. The median (interquartile range) duration of inpatient treatment in the ESD group was 8 days (7-11). In all, $74.3 \%$ needed IV antibiotics because of failure to respond to oral antibiotics, $10.2 \%$ had a pathogen requiring IV antibiotic therapy and $15.5 \%$ had severe exacerbations necessitating inpatient admission. 


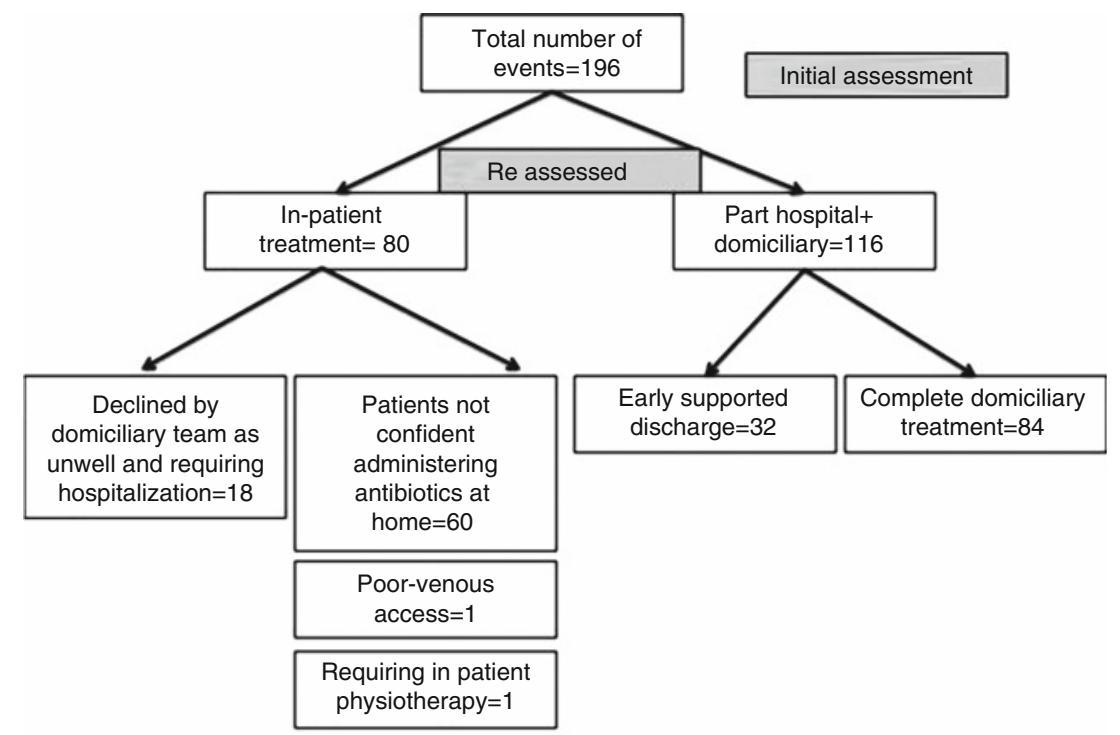

Figure 1. Flowchart showing initial assessment and recruitment of patients for domiciliary IV antibiotic therapy.

Table 1. Characteristics of the study population

\begin{tabular}{|c|c|c|c|c|}
\hline & $\begin{array}{l}\text { Inpatient group for } 14 \text { days } \\
\qquad(\mathrm{N}=36)\end{array}$ & $\begin{array}{l}\text { Early supported discharge } \\
\qquad(\mathrm{N}=23)\end{array}$ & $\begin{array}{l}\text { Domiciliary IV group } \\
\qquad(\mathrm{N}=52)\end{array}$ & $\mathrm{P}$ value $\mathrm{a}^{\mathrm{a}}$ \\
\hline Age & $71(62-76)$ & $65(56-69)$ & $61(63-69)$ & 0.0008 \\
\hline Gender (\% female) & $63.9 \%$ & $65.2 \%$ & $41.7 \%$ & 0.001 \\
\hline Smoking status Never/Ex/Current & $73.8 \% / 25 \% / 1.2 \%$ & $65.2 \% / 30.5 \% / 4.3 \%$ & $51.9 \% / 44.2 \% / 3.9 \%$ & $0.005 / 0.01 / 0.4$ \\
\hline BMI & $25.5(21.5-30.5)$ & $24.5(22-33)$ & $25(22-28)$ & 0.8 \\
\hline High BMI $>30 \mathrm{~kg} / \mathrm{m}^{2}$ & $5.6 \%$ & $4.3 \%$ & $11.5 \%$ & 0.1 \\
\hline $\mathrm{IHD}$ & $16.7 \%$ & $17.4 \%$ & $11.5 \%$ & 0.5 \\
\hline Asthma & $25 \%$ & $47.8 \%$ & $28.8 \%$ & 0.001 \\
\hline COPD & $41.7 \%$ & $13 \%$ & $11.5 \%$ & $<0.0001$ \\
\hline Previous malignancy & $5 \%$ & $8.7 \%$ & $13.5 \%$ & 0.09 \\
\hline ABPA on long term steroids & $5.6 \%$ & $8.7 \%$ & $5.8 \%$ & 0.6 \\
\hline Diabetes mellitus & $11.1 \%$ & $8.7 \%$ & $2 \%$ & 0.03 \\
\hline$\%$ DM requiring insulin & $0 \%$ & $0 \%$ & $0 \%$ & - \\
\hline Pre therapy $\mathrm{FEV}_{1}(\mathrm{~L})$ & $1.1(0.9-1.4)$ & $1.4(1-1.8)$ & $1.4(1-1.9)$ & 0.06 \\
\hline $\mathrm{FEV}_{1}$ (\% predicted) & $54.7 \%$ & & & \\
\hline Pre therapy FVC (L) & $1.9(1.5-2.3)$ & $2.3(1.7-2.8)$ & $2.4(2-2.9)$ & 0.007 \\
\hline FVC (\% predicted) & $66.5 \%$ & & & \\
\hline Pre therapy ISWT $(\mathrm{m})$ & $45(15-125)$ & $130(40-270)$ & $250(190-420)$ & 0.02 \\
\hline Inhaled corticosteroids & $72.5 \%$ & $91.3 \%$ & $82.7 \%$ & 0.004 \\
\hline Dose of ICS (micrograms) & $500(250-500)$ & $500(250-500)$ & $500(250-500)$ & 0.2 \\
\hline Dose of oral steroid $(\mathrm{mg})$ & $5(2.5-5)$ & $5(2.5-5)$ & $5(2.5-5)$ & 1 \\
\hline Long term antibiotic for chest & $10 \%$ & $4.3 \%$ & $7.7 \%$ & 0.2 \\
\hline$\%$ Colomicin (neb) & $25 \%$ & $0 \%$ & $50 \%$ & $<0.0001$ \\
\hline \% Gentamicin (neb) & $0 \%$ & $100 \%$ & $0 \%$ & $<0.0001$ \\
\hline$\%$ Clarithromycin (oral) & $75 \%$ & $0 \%$ & $50 \%$ & $<0.0001$ \\
\hline \% Coamoxiclav (oral) & $0 \%$ & $0 \%$ & $0 \%$ & - \\
\hline
\end{tabular}

Abbreviations: ABPA, allergic bronchopulmonary aspergillosis; BMI, body mass index; COPD, chronic obstructive pulmonary disease; DM, diabetes mellitus; $\mathrm{FEV}_{1}$, forced expiratory volume in $1 \mathrm{~s}$; FVC, forced vital capacity; ICS, inhaled corticosteroid; IHD, ischaemic heart disease; ISWT, incremental shuttle walk test; neb, nebulized.

${ }^{a} P$ values comparing baseline and pre-therapy characteristics of the groups.

Patient selection

A total of 196 patients were referred and thereby assessed for domiciliary IV antibiotic therapy.

\section{Baseline characteristics}

Of the total 80 episodes admitted to hospital for 14 days, there were a total of 36 patients who received IV therapy on one or more occasion. For the ESD group, of the 32 episodes, 23 patients received IV therapy on one or more occasions. For the domiciliary group, of the 84 episodes, 52 patients received IV therapy on one or more occasions. The characteristics of the individual patients in the cohort are shown in Table 1. The three groups differed at start of IV therapy by age, gender, smoking status, comorbidities, pretherapy FVC and exercise capacity. The group receiving inpatient IV therapy was older, had more patients who had coexistent COPD, and had less number of patients with coexistent asthma and previous malignancy. In addition, this group had lower baseline spirometry and exercise capacity compared to the ESD or domiciliary group. 


\section{Sputum microbiology}

Sputum was sent for qualitative microbiology in all patients prior to starting IV antibiotic therapy (see Table 2). In all groups, the most common microorganism identified was Pseudomonas aeruginosa. The groups add up to more than $100 \%$ as some patients had more than 1 pathogen isolated.

Treatment used

Ten different types of IV antibiotics (Table 3) were used alone or in combination.

Table 2. Microorganisms isolated at the beginning of intravenous therapy

\begin{tabular}{|c|c|c|c|}
\hline Microorganisms isolated & $\begin{array}{l}\text { Inpatient group } \\
\text { for } 14 \text { days } \\
(\mathrm{N}=80 \\
\text { episodes })\end{array}$ & $\begin{array}{c}\text { Early } \\
\text { supported } \\
\text { discharge } \\
(\mathrm{N}=32 \\
\text { episodes) }\end{array}$ & $\begin{array}{c}\text { Domiciliary } \\
\text { group } \\
\text { ( } \mathrm{N}=84 \\
\text { episodes) }\end{array}$ \\
\hline Pseudomonas aeruginosa & $48.8 \%$ & $28.1 \%$ & $34.5 \%$ \\
\hline Coliforms & $11.3 \%$ & $15.6 \%$ & $17.9 \%$ \\
\hline $\begin{array}{l}\text { MRSA (methicillin-resistant } \\
\text { Staphylococcus aureus) }\end{array}$ & $7.5 \%$ & $3.1 \%$ & $1.2 \%$ \\
\hline $\begin{array}{l}\text { MSSA (methicillin-sensitive } \\
\text { Staphylococcus aureus) }\end{array}$ & $3.8 \%$ & $6.3 \%$ & $9.5 \%$ \\
\hline Haemophilus influenzae & $8.8 \%$ & $15.6 \%$ & $32.1 \%$ \\
\hline Streptococcus pneumoniae & $3.8 \%$ & $6.3 \%$ & $14.3 \%$ \\
\hline Moraxella catarrhalis & $5 \%$ & $6.3 \%$ & $13.1 \%$ \\
\hline Mixed normal flora & $13.8 \%$ & $21.9 \%$ & $28.6 \%$ \\
\hline
\end{tabular}

Table 3. Intravenous antibiotic used

\begin{tabular}{lc}
\hline Antibiotic used & $\%$ \\
\hline Ceftazidime & 48.9 \\
Gentamicin & 14.8 \\
Ceftriaxone & 12.7 \\
Tazocin & 9.7 \\
Amoxicillin with clavulanic acid & 5.1 \\
Meropenem & 4 \\
Vancomycin & 2.6 \\
Colomycin & 2 \\
Flucloxacillin & 2 \\
Cefuroxime & 1.5 \\
\hline
\end{tabular}

Domiciliary IV therapy produces similar clinical outcomes compared to inpatient therapy

There was significant improvement in the $\mathrm{FEV}_{1}, \mathrm{FVC}$, incremental shuttle walking test, 24-h sputum volume, sputum bacterial clearance, parameters of inflammation (white cell count, C-reactive protein and erythrocyte sedimentation rate), Leicester Cough Questionnaire score and St George's Respiratory Questionnaire score from day 1 to day 14, in all groups (Table 4).

Domiciliary IV therapy safety (in our study cohort)

Morbidity was recorded in $13.8 \%$ in the inpatient group as compared to $9.4 \%$ in the ESD group and $14.2 \%$ in the domiciliary IV group. The main morbidities developed in all the groups were haemoptysis, heart failure and stroke. In the inpatient group $13.8 \%$ had complications (of which $63.6 \%$ had haemoptysis, $27.4 \%$ heart failure and 9\% stroke). In the ESD group, 9.4\% developed complications (of which $66.7 \%$ had haemoptysis and $33.3 \%$ had heart failure). In the domiciliary group $14.2 \%$ had complications (of which $58.3 \%$ had haemoptysis, $25 \%$ heart failure and $16.7 \%$ had

Table 5. Comparison of mortality, morbidity and safety between the three groups

\begin{tabular}{|c|c|c|c|}
\hline Complications & $\begin{array}{l}\text { Inpatient } \\
\text { group for } \\
14 \text { days } \\
(\mathrm{N}=80 \\
\text { episodes) }\end{array}$ & $\begin{array}{l}\text { Early supported } \\
\text { discharge } \\
(\mathrm{N}=32 \\
\text { episodes })\end{array}$ & $\begin{array}{l}\text { Domiciliary } \\
\text { IV group } \\
\text { (N=84 } \\
\text { episodes })\end{array}$ \\
\hline 14-day mortality & $0 \%$ & $0 \%$ & $0 \%$ \\
\hline 14-day morbidity & $11(13.8 \%)$ & $3(9.4 \%)$ & $12(14.2 \%)$ \\
\hline $\begin{array}{l}\text { Readmission within } \\
30 \text { days }\end{array}$ & 11 (13.8\%) & $4(12.5 \%)$ & 12 (14.2\%) \\
\hline Allergy to antibiotic & $1(1.2 \%)$ & $0 \%$ & $1(1.2 \%)$ \\
\hline $\begin{array}{l}\text { Side effects with } \\
\text { antibiotic }\end{array}$ & $4(5 \%)$ & $2(6.3 \%)$ & $4(4.7 \%)$ \\
\hline Anaphylaxis & $0 \%$ & $0 \%$ & $0 \%$ \\
\hline Clostridium difficile & $0 \%$ & $0 \%$ & $0 \%$ \\
\hline $\begin{array}{l}\text { Intravenous access- } \\
\text { related complications } \\
\text { (including line sepsis, } \\
\text { line blockage, line fell } \\
\text { out) }\end{array}$ & $0 \%$ & $2(6.3 \%)$ & $3(3.6 \%)$ \\
\hline Norovirus & $1(1.25 \%)$ & $0 \%$ & $0 \%$ \\
\hline
\end{tabular}

Table 4. Clinical outcomes measured on day 1 and day 14

\begin{tabular}{|c|c|c|c|c|c|c|c|c|c|}
\hline & \multicolumn{3}{|c|}{$\begin{array}{l}\text { Inpatient group for } 14 \text { days }(\mathrm{N}=80 \text { ), } \\
\text { median (interquartile range) }\end{array}$} & \multicolumn{3}{|c|}{$\begin{array}{l}\text { Early supported discharge }(\mathrm{N}=32) \text {, } \\
\text { median (interquartile range) }\end{array}$} & \multicolumn{3}{|c|}{$\begin{array}{l}\text { Domiciliary IV group ( } \mathrm{N}=84 \text { ), } \\
\text { median (interquartile range) }\end{array}$} \\
\hline & Day 1 & Day 14 & $\mathrm{P}$ value $\mathrm{e}^{\mathrm{a}}$ & Day 1 & Day 14 & $\mathrm{P}$ value $\mathrm{a}^{\mathrm{a}}$ & Day 1 & Day 14 & $\mathrm{P}$ value $\mathrm{e}^{\mathrm{a}}$ \\
\hline ISWT (m) & $45(15-125)$ & $120(30-190)$ & $<0.0001$ & $130(40-270)$ & $230(80-340)$ & 0.009 & $250(190-420)$ & $350(250-450)$ & $<0.0001$ \\
\hline $\mathrm{FEV}_{1}(\mathrm{~L})$ & $1.2(0.9-1.3)$ & $1.2(1-1.3)$ & 0.02 & $1.3(1-1.8)$ & $1.5(1-1.9)$ & 0.03 & $1.4(1-1.9)$ & $1.6(1.2-2.1)$ & 0.004 \\
\hline FVC (L) & $1.9(1.5-2.2)$ & $2(1.6-2.4)$ & 0.0009 & $2.3(1.7-2.8)$ & $2.3(2.1-2.9)$ & 0.02 & $2.4(2-3)$ & $2.8(2.2-3.5)$ & 0.04 \\
\hline$\%$ PPM & $95 \%$ & $53.8 \%$ & $<0.0001$ & $74.2 \%$ & $19.4 \%$ & $<0.0001$ & $82.1 \%$ & $44 \%$ & $<0.0001$ \\
\hline $\operatorname{WCC}^{\mathrm{a}}\left(10^{9} / \mathrm{l}\right)$ & $10.7(8.7-13.3)$ & $8.9(7.1-11.1)$ & $<0.0001$ & $9.1(7.4-13)$ & $7.5(5.8-10.3)$ & 0.05 & $10.1(8.1-13)$ & $7.3(5.8-9.6)$ & $<0.0001$ \\
\hline CRP (mg/l) & 31 (14-125) & $9.5(5-15.5)$ & $<0.0001$ & $19(5-127)$ & $5.5(1-10.5)$ & 0.0004 & $46(9-138)$ & $3(1-6)$ & $<0.0001$ \\
\hline $\operatorname{ESR}(\mathrm{mm} / \mathrm{h})$ & $41(21-63)$ & $21(13-36)$ & $<0.0001$ & $33(19-52)$ & $23.5(11.5-37.5)$ & 0.02 & $28(16-38)$ & $16(8-23)$ & $<0.0001$ \\
\hline
\end{tabular}


Table 6. Subgroup analysis: clinical outcomes measured on day 1 and day 14 in individual patients

\begin{tabular}{|c|c|c|c|c|c|c|c|c|c|}
\hline & Day 1 & Day 14 & $\mathrm{P}$ value & Day 1 & Day 14 & $\mathrm{P}$ value & Day 1 & Day 14 & $\mathrm{P}$ value \\
\hline ISWT (m) & $120(30-200)$ & $200(100-300)$ & 0.0004 & $180(60-280)$ & $270(160-350)$ & 0.009 & $250(10-240)$ & $340(210-440)$ & 0.0006 \\
\hline $\mathrm{FEV}_{1}(\mathrm{I})$ & $1.1(0.9-1.4)$ & $1.3(0.9-1.4)$ & 0.04 & $1.4(1-1.9)$ & $1.5(1.1-1.9)$ & 0.1 & $1.4(1.1-1.9)$ & $1.6(1.2-2)$ & $<0.0001$ \\
\hline FVC (I) & $1.9(1.5-2.3)$ & $2(1.6-2.5)$ & 0.01 & $2.3(1.7-2.9)$ & $2.4(2.1-2.9)$ & 0.02 & $2.4(1.9-2.9)$ & $2.7(2.2-3.2)$ & 0.002 \\
\hline$\%$ PPM & $92.5 \%$ & $22.2 \%$ & $<0.0001$ & $65.2 \%$ & $13 \%$ & $<0.0001$ & $78.8 \%$ & $15.4 \%$ & $<0.0001$ \\
\hline $\begin{array}{l}\text { WCC }^{a} \\
\left(\times 10^{9} / \mathrm{l}\right)\end{array}$ & $10.5(9.1-13.5)$ & $8.7(6.5-11.6)$ & 0.003 & $9.7(7.6-13.3)$ & 7 (5.5-9.8) & 0.07 & $16.1(7.7-11.6)$ & $7.5(5.1-9.7)$ & $<0.0001$ \\
\hline CRP (mg/l) & $48.5(16.5-83.5)$ & $8.7(6.5-11.6)$ & 0.001 & $42(8-104)$ & $5.5(1-9)$ & 0.002 & 47 (11-135) & $4(1-9)$ & $<0.0001$ \\
\hline $\operatorname{ESR}(\mathrm{mm} / \mathrm{h})$ & $41(21.5-78)$ & $27(16-42)$ & 0.03 & $34(18-51)$ & $23.5(11.5-37.5)$ & 0.01 & $29.5(17.5-42)$ & $17(13-28)$ & 0.0004 \\
\hline
\end{tabular}

stroke). No mortality was recorded in the groups. Thirty-day readmission rates were similar in all groups and the reason for readmission was further exacerbation of bronchiectasis, in all episodes recorded. Side effects with antibiotics, including allergies, developed in 5\% in the inpatient group as compared to $6.3 \%$ and $4.7 \%$ in the ESD group and the domiciliary IV group, respectively. There was no IV access-related complications in the inpatient group in comparison to $6.3 \%$ in the ESD group $(50 \%$ had line blockage and in 50\% the line fell out) and 3.6\% in the domiciliary IV group (60\% had line blockage, $20 \%$ line sepsis and in $20 \%$ the line fell out). These results are summarized in Table 5.

\section{Bed days saved}

Together, the domiciliary IV therapy and the ESD group saved a total of 1,443 bed days. This allowed freeing up inpatient beds, which could be reallocated.

\section{Subgroup analysis of individual patients}

Of the total 196 episodes of IV antibiotics, a total of 111 patients received treatment. There were 36 individual patients who were admitted as inpatients, of whom 16 required more than one course of IV antibiotics. In the ESD group, 23 individual patients received IV antibiotics, of whom 6 had more than one course of antibiotics. In the domiciliary group, 52 individual patients received IV antibiotics, of whom 19 had more than one course of antibiotics. The first event of individual patients was used. There were similar results in individual patient outcomes (Table 6) as compared to outcomes of all episodes (Table 3), in all groups.

\section{DISCUSSION}

Main findings

We have introduced domiciliary IV antibiotic therapy in patients with bronchiectasis in a tertiary centre in the UK, by using a team to promote patient-centred domiciliary therapy instead of inpatient treatment. Although domiciliary IV antibiotic therapy is common in cystic fibrosis and other infectious diseases, this is the first large study reporting IV antibiotic therapy in bronchiectasis. This prospective study found that in the patients assessed as suitable by the home IV team, domiciliary IV antibiotic therapy in bronchiectasis is clinically effective and safe.
This study has shown that domiciliary therapy with IV antibiotics results in similar clinical outcomes compared to inpatient therapy. There was significant improvement in exercise capacity, spirometry, sputum volume reduction, markers of systemic inflammation, microbial clearance and health-related quality of life at the end of therapy, in both groups. A subgroup analysis of individual patients, in all three groups, showed similar outcomes to the analysis of all episodes.

Morbidity was recorded in $13.8 \%$ in the inpatient group as compared to $9.4 \%$ in the ESD group and $14.2 \%$ in the domiciliary IV group. No mortality was recorded in any of the three groups. Readmission rates at 30 days were $<15 \%$ in all groups. Side effects with antibiotics, including allergies, were similar $(<7 \%)$ in all groups. There was no IV access-related complications in the inpatient group in comparison to $6.3 \%$ in the ESD group and $3.6 \%$ in the domiciliary IV group. No cases of Clostidium difficile were recorded in the groups. This study shows that in our centre, domiciliary IV (both ESD and domiciliary de novo) antibiotic therapy is a safe and efficient model of health-care delivery in the treatment of exacerbations in non-cystic fibrosis bronchiectasis.

Over the past 5 years, 116 episodes of inpatient admissions were avoided by this service, which meant releasing 1,443 bed days, which could be reallocated. It is known that the acquisition costs of antibiotics for domiciliary IV therapy can sometimes exceed inpatient alternatives. ${ }^{16}$ However, in our centre, antibiotic regimen was the same for both groups. Hence, directs costs including antibiotics, saline flushes and equipment did not come at any higher costs than that needed for inpatient therapy.

Interpretation of findings in relation to previously published work Owing to lack of research in non-cystic fibrosis bronchiectasis, data are often extrapolated from studies done in cystic fibrosis, to guide therapy. To date, there has been only one blinded, randomized control trial investigating the role of domiciliary IV antibiotics versus hospital treatment in cystic fibrosis-related bronchiectasis. ${ }^{17}$ This was done in 19 patients and all patients had at least 2-3 days treatment in hospital before being started on domiciliary IV antibiotic treatment. We accept that our study was not a randomized trial, but this is a large study done in a tertiary centre in the UK, where we have been able to demonstrate that domiciliary IV antibiotics for acute exacerbations can be done safely and effectively. 
Ideally, domiciliary treatment should be as effective as inpatient treatment and clinical improvement not sacrificed on the basis of economic considerations and convenience. ${ }^{18}$ Domiciliary treatment allows patients to be treated at home, which should translate into better quality of life and decreased risks of inpatient errors and nosocomial complications. ${ }^{19}$ In addition, domiciliary IV antibiotics provide the opportunity to deliver more patient-centred care than in the traditional inpatient setting. ${ }^{20}$ All these benefits support the aim of the UK healthcare quality strategy, with emphasis on patient-centred and ambulatory care. $^{20}$ We have been able to establish this service with careful risk assessment and management, and have been able to demonstrate that this service is safe and clinically effective. This is of significant importance in bronchiectasis, where prompt treatment of exacerbations with appropriate antibiotics is one of the key aims in managing this chronic condition.

Strengths and limitations of this study

To the best of the authors' knowledge, this is the first large prospective cohort study assessing the safety and efficacy of domiciliary IV antibiotic therapy in non-cystic fibrosis bronchiectasis in the UK, where patients are middle aged and elderly and have pre-existing comorbid conditions. This study provides data that will help both primary and secondary care teams consider domiciliary therapy for bronchiectasis, if a service is available in their centre.

We accept that this study is not a randomized control trial. Inpatient or domiciliary treatment was up to the discretion of the patient and domiciliary team. Also, we did not assess the cost effectives that domiciliary treatment would have to the NHS. However, the main aim of this study was to establish a domiciliary IV antibiotic service for exacerbations in bronchiectasis and demonstrate the safety and efficacy of this service in our centre.

Implications for future research, policy and practice

A prospective randomized trial would consolidate our research findings. In patients deemed suitable for domiciliary treatment, domiciliary treatment either fully or as ESD is safe and efficacious.

\section{Conclusion}

In patients assessed as suitable by the home IV team, domiciliary IV antibiotics in bronchiectasis is clinically effective and was safe in our cohort of patients.

\section{COMPETING INTERESTS}

The authors declare no conflict of interest.

\section{FUNDING}

Dr Pallavi Bedi is funded by the Chief Scientist Office. No additional funds were available for this study.

\section{REFERENCES}

1 Wilson CB, Jones PW, O'Leary CJ, Cole PJ, Wilson R. Validation of the St George's Respiratory Questionnaire in bronchiectasis. Am J Respir Crit Care Med 1997; 156: 536-541.

2 Pasteur MC, Bilton D, Hill AT, British Thoracic Society Bronchiectasis non-CF Guideline Group. British Thoracic Society guideline for non-CF bronchiectasis. Thorax 2010; 65(Suppl 1): i1-58.

3 Donati MA, Guenette G, Auerbach H. Prospective controlled study of domiciliary and inpatient therapy of cystic fibrosis pulmonary disease. J Pediatr 1987; 111: 28-33.

4 Strandvik B, Hjelte L, Malmborg AS, Widen B. Domiciliary intravenous antibiotic treatment of patients with cystic fibrosis. Acta Paediatr 1992; 81: 340-344.

5 Bramwell EC, Halpin DM, Duncan-Skingle F, Hodson ME, Geddes DM. Domiciliary treatment of patients with cystic fibrosis using the 'Intermate': the first year's experience. J Adv Nurs 1995; 22: 1063-1067.

6 Wolter JM, Bowler SD, Nolan PJ, McCormack JG. Domiciliary intravenous therapy in cystic fibrosis: a prospective randomized trial examining clinical, quality of life and cost aspects. Eur Respir J 1997; 10: 896-900.

7 Thornton J, Elliott RA, Tully MP, Dodd M, Webb AK. Clinical and economic choices in the treatment of respiratory infections in cystic fibrosis: comparing inpatient and domiciliary care. J Cyst Fibros 2005; 4: 239-247.

8 Birmingham J. Decision matrix for selection of patients for a domiciliary infusion therapy programme. J Intraven Nurs 1997; 20: 258-263.

9 Cooper C, Cattermole B. Principles of delivering safe intravenous therapy in the community setting. $\mathrm{Br} J$ Domiciliary Health 2006; 1: 6-8.

10 Corwin P, Toop L, McGeogh G, Than M, Wynn-Thomas S, Wells JE et al. Randomised controlled trial of intravenous antibiotic treatment for cellulitis at domiciliary compared with inpatient. BMJ 2005; 330: 129.

11 Birring SS, Prudon B, Carr AJ, Singh SJ, Morgan MD, Pavord ID. Development of a symptom specific health status measure for patients with chronic cough: Leicester Cough Questionnaire (LCQ). Thorax 2003; 58: 339-343.

12 Jones PW, Quirk FH, Baveystock CM, Littlejohns P. A self-complete measure of health status for chronic airflow limitation: the St Georges' Respiratory Questionnaire. Am Rev Respir Dis 1992; 145: 1321-1327.

13 British Thoracic Society and Association for Respiratory Technology and Physiology. Guidelines for the measurement of respiratory function. Respir Med 1994; 88: 165-194.

14 Singh SJ, Morgan MDL, Scott SC, Walters D, Hardman AE. The development of a shuttle walking test of disability in patients with chronic airways obstruction. Thorax 1992; 47: 1019-1024.

15 Murray MP, Turnbull K, Macquarrie S, Pentland JL, Hill AT. Validation of the Leicester Cough Questionnaire in non-cystic fibrosis bronchiectasis. Eur Respir J 2009; 34: 125-131.

16 Portez DM. Outpatient parenteral antibiotic therapy. Int J Antimicrob Agents 1995; 5: 9-12.

17 Wolter JM, Bowler SD, Nolan PJ, McCormack JG. Home intravenous therapy in cystic fibrosis: a prospective randomized trial examining clinical, quality of life and cost aspects. Eur Respir J 1997; 10: 896-900.

18 Pond MN, Newport M, Joanes D, Conway SP. Domiciliary versus inpatient intravenous antibiotic therapy in the treatment of young adults with cystic fibrosis. Eur Respir J 1994; 7: 1640-1644.

19 Nguyen $\mathrm{HH}$. Hospitalist to home: outpatient parenteral antimicrobial therapy at an academic center. Clin Infect Dis 2010; 51(Suppl 2): S220-S223.

20 Chapman AL, Seaton RA, Cooper MA, Hedderwick S, Goodall V, Reed C et al. on behalf of the BSAC/BIA OPAT Project Good Practice Recommendations Working Group. Good practice recommendations for outpatient parenteral antimicrobial therapy (OPAT) in adults in the UK: a consensus statement. J Antimicrob Chemother 2012; 67: 1053-1062.

(i) $\Theta$ This work is licensed under a Creative Commons AttributionNonCommercial-NoDerivatives 4.0 International License. The images or other third party material in this article are included in the article's Creative Commons license, unless indicated otherwise in the credit line; if the material is not included under the Creative Commons license, users will need to obtain permission from the license holder to reproduce the material. To view a copy of this license, visit http:// creativecommons.org/licenses/by-nc-nd/4.0/ 